\title{
28 Research Square \\ Self-Care in the Older Adult Population With Chronic Disease: Concept Analysis
}

Jawhrah ALQAHTANI ( $\nabla$ jmalqahtani@ksu.edu.sa )

King Saud University

Ibtesam ALQAHTANI

King Saud University

\section{Research Article}

Keywords: self-care, chronic disease, adult population, concept analysis.

Posted Date: October 13th, 2021

DOl: https://doi.org/10.21203/rs.3.rs-960884/v1

License: (9) This work is licensed under a Creative Commons Attribution 4.0 International License. Read Full License 


\section{Abstract}

Background. Chronic disease care is considered a challenging dilemma for health organizations' sustainability and patient health. Self-care is key to chronic disease management and is substantially important in all aspects of health and levels of care. In the past years, research regarding self-care in the context of chronic disease has evolved, yet this complex concept continues to be ambiguous and has not been clearly conceptualized in the literature. A discussion of an in-depth concept analysis of self-care in the older adult population with chronic disease and an outline of its defining common attributes, referents, antecedents, consequences, and related concepts.

Methods. An extensive review of the literature concerning the concept of self-care in the older adult population with chronic disease was conducted using different databases. Literature from nursing and other disciplines was selected to differentiate this concept from other related concepts. Rodgers's evolutionary methodology of concept analysis was used to investigate the concept of self-care in detail to better understand its meanings in the context of chronic disease.

Results. Multiple definitions of self-care exist, and a consensus definition was not shown to have been achieved across disciplines. The common attributes, referents, antecedents, consequences, and related concepts were identified, and a model case was constructed to clarify the concept of self-care in the context of the older adult population living with chronic disease.

Conclusion. This concept analysis provides a theoretical definition of self-care of the older adult population living with chronic disease to offer nurses and others insight into the concept, which will ultimately provide a foundation for further research needed in the areas of clinical practice, policy, and education. Identification of the core of the self-care concept affords professionals and researchers the ability to identify appropriate practice priorities, enhance current practices, and develop theories regarding self-care, leading to improvements in patient care and outcomes.

\section{Background}

Chronic disease care is a challenging issue for clients' well-being and a burden for global healthcare, as it represents one of the primary expenditures of healthcare systems (Centers for Disease Control and Prevention [CDC], 2018; World Health Organization [WHO], 2019). Existing evidence supports the concept of self-care as a component of care for individuals living with chronic conditions and is critical in the prevention, control, and management of chronic disease (Schulman-Green, 2012). One response to the high prevalence of chronic disease among the older adult population is the promotion of self-care via encouraging greater involvement of chronically ill individuals in their own care to improve quality of life and reduce healthcare costs (WHO, 2019). Active participation, empowerment, and responsibility are considered core principles in chronic disease management (WHO, 2019). All these behaviors require additional knowledge, motivation, and skills, directing to self-care (Riegel et al., 2019; Schulman-Green, 2012). Promotion of self-care is therefore essential and requires the patient to assume an active role in 
their disease management, but there is a lack of consensus on the definition and scope of self-care (Riegel et al., 2019). Thus, clarity on the concept of self-care and a meticulous analysis of its concept is necessary to better understand it, which can inform nursing care and facilitate the implementation of a self-care approach for chronic conditions.

Historically, the concept of self-care has been rooted in the discipline of nursing and was first introduced in the late 1950s, and then officially defined by Dorothea Orem, a nurse theorist, referred to learned, positive, and practical activities performed by individuals within their own time frames to maintain health and well-being while continuing their personal development (Orem, 1959). This concept as a process involves the domains of shifting responsibility back onto the individual, focusing on illness needs, and living with disease (Orem, 1959). By 1971, Orem had built a nursing theory based on the concept of selfcare, including the self-care theory (which describes and explains self-care), self-care deficit theory (which explains how nursing can assist individuals when they are unable to achieve self-care independently), and the theory of nursing systems (which describes the relationships required for nursing itself to exist), thereby providing nursing with a framework to direct practice and linking self-care concepts with nursing practice (McEwen \& Wills, 2014).

Within sociology, Levin (1979) was one of the first to define the concept of self-care as a process in which people take personal responsibility in the promotion of health, disease prevention, and treatment. In agreement with Levin, Idler in 1983 described self-care as activities that individuals undertake in promoting health, restoring health, preventing disease, and limiting illness (LeBlanc et al., 2018). In 1984, the WHO issued a first overarching definition of self-care and then developed a number of finer definitions in later years. Self-care was defined as the activities individuals undertake on their own behalf, either separately or in participative collaboration with professionals, intending to establish and maintain health and preventing and dealing with the disease (WHO, 1984). Later, the WHO (2013) expanded the definition of self-care beyond the capacity to act solely by an individual to the ability of individuals, families, and communities to maintain and promote health, prevent disease, and cope with disease and disability, with or without the support of healthcare providers or professional assistance. The primary purpose of this concept analysis is to examine the state of knowledge and to provide a conceptual understanding of selfcare while defining self-care's common attributes (characteristics), referents (contextual information), antecedents (events prior to self-care), consequences (what happens after self-care), and related concepts (concepts that have a relationship with chronic disease self-care).

\section{Methods}

An extensive review of the literature was performed using several databases, including CINAHL, Cochrane Library, PubMed, Ovid, EBSCO, Medline, PsycINFO, EMBASE, and SocINDEX, with no limit set for the date of publication. Databases were searched utilizing the following keywords: "self-care," "chronic disease," "adult population," and "concept analysis." The targeted population consisted of the adult population with chronic disease. The sample selection criteria were as follows: articles written in the English language, made available in full text in the selected databases, which showed evidence in the title, 
abstract, or in its other structures, of aspects relating to the concept of self-care. Literature searches generated 9,262 scholarly articles to be identified, from 1950 to 2021. Each article was screened electronically by abstract and title to remove duplicates and include materials with a strong focus on selfcare. Thirty-one articles that met the criteria were obtained for further screening, and then 17 articles formed part of the self-care concept analysis' sample. The majority of these 17 research articles published between 1979 and 2019 were retrieved from nursing and medical journals in to provide analysis from an evidence-informed perspective. After the phase of selecting the literature that served as the basis for analysis of the concept, each article was analyzed by means of the evolutionary methodology proposed by Rodgers (1989), who understands the development of a concept as a cycle that continues over time and within a particular context (Rodgers \& Knafl, 2000). Each article was objectively read, and during reading, fragments of text were identified and highlighted which referred to attributes, referents, antecedent, and consequences of the concept of self-care, as well as concepts related to self-care. The information acquired also enabled the construction of the relevant model case to outline misinterpretations related to the concept of self-care, along with a clear definition of the concept.

\section{Results:}

\section{Literature Review}

The following section focuses on discussing the main findings in the literature.

Riegel et al. (2019) and Høy et al. (2007) examined the confusions related to the concept of self-care and its usage within healthcare and concluded with a holistic explanation of the concept to better help professionals in incorporating the approach of self-care into patient care. Researchers viewed self-care as a process for health, a health capability, and a personal activity. Self-care, as a process, is a health developmental stage related to well-being and illness, which is performed either under the direct care of professionals, totally independently by patients, or in collaboration between both partners (Høy et al., 2007; Riegel et al., 2019). As a health capability, self-care is defined as a potential action directed toward self-care needs, common goals, and health issues (Riegel et al., 2019). As an activity, self-care involves physical, social, mental, and spiritual actions, which are learned and consciously carried out by a patient (Høy et al., 2007; Riegel et al., 2019). Researchers have emphasized that all these activities are influenced by the individual's perception, financial, and social conditions; are under personal control; are situationdriven; and are directed toward individual goals (Høy et al., 2007; Riegel et al., 2019). They concluded that self-care is performed by patients in conjunction with their families and healthcare providers to maintain health, build self-esteem, and reach autonomy; professionals can better equip patients with the resources and skills necessary to effectively participate in their disease management in the long term.

Richard and Shea (2011), Wilkinson and Whitehead (2009), and Thorne et al. (2002) explored the concept and the factors that influenced self-care activities in patients with chronic disease. According to these researchers, self-care is seen as a multidimensional construct and a broader concept that subsumes selfmonitoring, self-management, and symptom management. All these concepts fall within the domain of 
self-care, often referring to a patient's ability and performance of activities related to acute and chronic health conditions, and for health promotion and maintenance. Self-care was also described as a dynamic process, strategy, or activity by which an individual with a health problem intentionally carries out activities to manage healthcare conditions (Richard \& Shea, 2011; Wilkinson \& Whitehead, 2009). The researchers clarified that this concept entailed a collaborative partnership and interactions between the individual and the healthcare providers, helping to acquire better knowledge about the clinical issues and patient needs and to identify areas of misunderstanding by patients in relation to their own care. Researchers identified that self-care, in combination with health literacy, personal skills, assertiveness, families, providers, and social support, helps enhance patients' own care and improves compliance with health activities (Richard \& Shea, 2011; Thorne et al., 2002; Wilkinson \& Whitehead, 2009). Having ongoing communication and providing and receiving social support were reported as a means of selfcare and health maintenance in adult patients (Richard \& Shea, 2011; Thorne et al., 2002; Wilkinson \& Whitehead, 2009).

Sundsli et al. (2013) and Blankers et al. (2011) discussed the true meaning of self-care and its correlations with other concepts. These researchers defined self-care as either an action or task that is meant for all populations to maintain a satisfactory quality of life. They emphasized that self-care encompasses coping, self-management, and self-help; all these concepts are directly linked to self-care, as all are involved in actions to enhance patients' self-care abilities (Blankers et al., 2011; Sundsli et al., 2013). They highlighted that self-help is an overarching form of self-administered treatment, intending to educate patients about their disease and equip them with the necessary skills related to their disorders. It has also been determined that understanding their conditions and sharing responsibility opens a space for individuals with chronic disease to engage in aspects of self-care they feel skilled in and to continue learning, thereby developing a greater level of competency in self-care and improving confidence and health outcomes over time (Blankers et al., 2011; Sundsli et al., 2013). Further to this finding, researchers have pointed out that the concept of self-management as related to self-care is often interpreted as a subset (Blankers et al., 2011; Sundsli et al., 2013).

\section{Concept Analysis of Self-Care:}

The following activities, as proposed by Rodgers (1989), were used during this concept analysis (1) identify the concept of interest (2) identify and select an appropriate sample from the relevant literature using a systematic approach and broad time frame (3) analyze data to identify characteristics of the concept (4) identify the attributes of the concept (5) identify the antecedents, consequences, and references of the concept where possible (6) identify concepts that are related to the term of interest (7) identify a model, real case of the concept (Rodgers \& Knafl, 2000).

\section{Defining Attributes of Self-Care}

According to Rodgers and Knafl (2000), attributes represent the primary accomplishment of concept analysis and assist in clarifying that concept by answering the following question: "What are the characteristics of the concept?" (p. 91). The prominent attributes of the self-care concept in the older 
adult population with chronic disease are revealed, including the process of looking after oneself (resulting in long-lasting individual benefits of self-care and maintaining general well-being); knowledge and education (health literacy); self-monitoring or self-control (ability and confidence) to perform certain activities; relationships (collaborative partnerships); action skills (capability) directed toward needs, goals, and health problems; and self-care activities (involves practicing physical, psychological, social, and spiritual self-care activities); informed decision-making, positive attitudes, active participation in changes, role management, resource utilization, and adherence to a self-care plan are also closely aligned to the self-care concept (Anderson, 1990; Blankers et al., 2011; Clark, 2003; Godfrey et al., 2011; Haug et al., 1989; Høy et al., 2007; LeBlanc et al., 2018; Levin, 1979; Lorig \& Holman, 2003; Moore et al., 2015; PetersKlimm, 2013; Richard \& Shea, 2011; Riegel et al., 2019; Schulman-Green, 2012; Sundsli et al., 2013; Wilkinson \& Whitehead, 2009).

\section{Referents of Self-Care}

Analysis of referents resulted in the identification of the common attributes of self-care, and 17 articles were used to define them. To ensure that the concept is examined in a holistic way and from different perspectives, and eventually, reaches a consensus, these most relevant articles were subdivided into three categories: articles about self-care concepts in general, self-care as specific to diagnosis, and articles about self-care and its link to chronic disease. From this analysis, the involvement of others in chronic disease patients' self-care activities, such as family members, care providers, and therapists, was a common outcome. However, a lack of consistency related to their roles and boundaries in self-care makes it difficult to unravel the actual roles of patients in their own care from others.

\section{Antecedents of Self-Care}

Antecedents are defined as events that take place before the advent of the concept, while consequences have occurred as a result of the concept in question (Rodgers \& Knafl, 2000). The three types of antecedents for self-care were found to be client-related (commitment, self-efficacy, self-motivation, selfesteem, availability of time, and mutual investment with chronic disease), healthcare provider-related (active participation, partners' relationship or support of and cooperation with the clients), and systemrelated (adequate sources; disease knowledge; social networks; and social, spiritual, mental, financial, cultural factors; Anderson, 1990; Blankers et al., 2011; Clark, 2003; Godfrey et al., 2011; Haug et al., 1989; Høy et al., 2007; LeBlanc et al., 2018; Levin, 1979; Lorig \& Holman, 2003; Moore et al., 2015; Peters-Klimm, 2013; Richard \& Shea, 2011; Riegel et al., 2019; Schulman-Green, 2012; Sundsli et al., 2013; Thorne et al., 2002; Wilkinson \& Whitehead, 2009).

\section{Consequences of Self-Care}

In contrast to antecedents, positive and negative consequences are defined as those events or incidents that occur as a result of the concept in question (Rodgers \& Knafl, 2000). Maintenance of health and wellbeing, enhancement of knowledge and awareness, increased adjustment with disease,alleviation of symptoms, increased self-esteem, enhanced active participation, decreased healthcare resource 
utilization, decreased risk of disease complications, the ability to acquire autonomy, and treatment adherence are the common consequences of improving patients' ability in self-care, thereby developing a higher level of competency in self-care (Blankers et al., 2011; Godfrey et al., 2011; LeBlanc et al., 2018; Moore et al., 2015; Peters-Klimm, 2013; Riegel et al., 2019; Schulman-Green, 2012). Having an independent attitude toward one's care process results in various consequences, including improved health status, improved health outcomes, enhanced functional ability, improved self-efficacy, increased patient satisfaction, and improved quality of life through education, social support, action skill development, and lifestyle changes (Clark, 2003; Høy et al., 2007; Lorig \& Holman, 2003; Richard \& Shea, 2011; Wilkinson \& Whitehead, 2009). Without engaging in self-care, negative consequences result, including poor performance capability, loss of power capabilities, increased dependency, decreased selfesteem and confidence, reduced well-being, decreased health outcomes, increased risk of disease complications, more healthcare visits, and negative physical and psychological states (Godfrey et al., 2011; Haug et al., 1989; LeBlanc et al., 2018; Levin, 1979; Thorne et al., 2002).

\section{Surrogate Terms and Concepts Related to Self-Care}

The following terms are related to self-care and are used interchangeably with the concept of self-care and have all appeared in nursing and non-nursing articles: active participation, coping, self-management, self-monitoring, self-efficacy, adherence, and enabling (LeBlanc et al., 2018; Moore et al., 2015; Sundsli et al., 2013). Active participation of individuals in their own conditions involves opportunities to engage in and influence decisions regarding care (Clark, 2003; Høy et al., 2007; Lorig \& Holman, 2003). Coping exists within the broader concept of self-care as an active component (Godfrey et al., 2011; Richard \& Shea, 2011). Self-management, self-monitoring, and self-efficacy are empowering approaches to care and are commonly associated with self-care, which implies their crucial roles in patient care as essential elements of chronic disease management, and involve a reaction and action phase (Haug et al., 1989; Moore et al., 2015). Self-management is a subcategory of self-care that empowers individuals to take charge of their own conditions and involves self-regulation skills (Blankers et al., 2011; Sundsli et al., 2013). Self-monitoring is a component of self-care in which an individual undertakes activities such as monitoring their symptoms or self-adjustment of their treatment and lifestyle as a result of selfawareness (Levin, 1979; Schulman-Green, 2012). Self-efficacy is both an antecedent and a consequence of self-care and refers to an individual's degree of confidence in their ability to self-manage and selfmonitor while requiring minimal support to reach their goals (Levin, 1979; Riegel et al., 2019). Adherence and enabling are associated with self-care throughout the literature, as both help give control, develop abilities, and produce an overall new balance in patients' lives (Peters-Klimm, 2013; Schulman-Green, 2012).

\section{Model Case}

This case has demonstrated the defining attributes, antecedents, and consequences of self-care. Ms. Smith is a 45-year-old female diagnosed with type I diabetes mellitus two years ago. As soon as she became aware of her diagnosis, she made it a goal to control her condition and committed to managing 
her care and taking responsibility for it herself. She acquired the essential knowledge and skills necessary to succeed in her self-care and maintain good diabetes control via participation in an educational program offered at the community center. In this program, she learned about the disease, its signs and symptoms, its complications, and its treatment options. She also identified ways to manage her own care independently, maintain her general well-being, and prevent disease-related complications. Since then, she has demonstrated an understanding of the relevant information, managed her condition, and followed her regimen, including diet, insulin administration, exercise adherence, foot care, and eye checkups. She has become capable of recognizing her needs, engaging in self-care actions, monitoring her blood glucose levels, recognizing physical systems as being hyperglycemic or hypoglycemic, adjusting her insulin intake accordingly, choosing a healthy lifestyle, and avoiding any stressors. She has participated in a group discussion with her family members, friends, healthcare team, and a support group related to living with diabetes mellitus. She has developed an emergency plan for if her self-action does not help in resolving her symptoms, such as reaching out for her provider's help for better disease control and family support. She has communicated regularly with her primary healthcare team when she has a concern or question about her symptoms. She has discussed and revised the management plan with her providers, and she has regular follow-up appointments to check her diabetes control. Up to this point, Ms. Smith has demonstrated self-care, maintaining of her condition, and diabetes control with no disease-related complications.

\section{Theoretical Definition of the Concept of Self-Care}

Based upon the identified attributes, antecedents, and consequences that were found in this analysis, the theoretical definition of self-care of the older adult population living with chronic disease is as follows: a health development process in which individuals with chronic disease make a naturalistic and informed decision to manage their condition independently (self-care management) and function effectively in taking care of their own health with minimal or no support of health-care providers, show ownership of self-care activities via active participation (self-care maintenance) in these activities, comply with necessary changes and long-term therapeutic regimens, enhance their self-efficacy by monitoring symptoms and solving problems caused by their disease, and incorporate effective self-care strategies into daily life to achieve, maintain, or promote maximum health and well-being, through interactions with healthcare providers.

\section{Discussion}

Self-care of the older adult population living with chronic disease is a complex and dynamic concept. Although much information on self-care is available, gaps in articulation and understanding of the concept are evident. The findings of this concept analysis indicated the common attributes of the concept of self-care, namely the process of looking after oneself, knowledge and education, selfmonitoring and self-control, relationships, action skills, self-care activities, informed decision-making, positive attitudes, active participation in changes, role management, resource utilization, and adherence. Three types of antecedents for self-care were identified to be client-related; healthcare provider-related; 
and system-related. The positive consequences mentioned were maintenance of health and well-being; enhancement of knowledge and awareness; increased adjustment with disease; alleviation of symptoms; increased self-esteem; enhanced active participation; decreased healthcare resource utilization; decreased risk of disease complications; improved ability to reach autonomy; improved treatment adherence; improved health status; improved health outcomes; enhanced functional ability; improved self-efficacy; increased patient satisfaction; and improved quality of life through education, social support, action skill development, and lifestyle changes. The described negative consequences include poor performance capability, loss of power capabilities, increased dependency, decreased self-esteem and confidence, reduced well-being, decreased health outcomes, increased risk of disease complications, more healthcare visits, and negative physical and psychological states. Seven concepts were related to self-care: coping, adherence, enabling, active participation, self-management, self-monitoring, and self-efficacy.

\section{Conclusions}

The term "self-care" is used broadly within the literature as an activity, process, model, method, or framework to improve chronic disease healthcare outcomes, yet it lacks clarity. This paper highlighted the definition of the concept of self-care in relation to its attributes, references, antecedents, consequences, and related concepts, which can be used as components of nursing practice to promote self-care by patients with chronic disease, as well as indicators for nursing assessment and for evaluation of nursing intervention. Findings generated from this concept analysis offer a better understanding of the needs of adult individuals living with chronic disease, help in understanding self-care as a multidimensional concept, and help to highlight a standardized approach to self-care as an essential component in the treatment of individuals with chronic disease.

This clarification of self-care can have implications for clinical nursing practice and research, therefore contributing to the body of knowledge and patients' care. Once nurses understand the concept of selfcare accurately, they can develop effective nursing interventions and theories to empower individuals in managing their conditions independently. Further research exploring self-care from the patient's perspective and encompassing all the factors and characteristics of the concept of self-care in this paper is necessary to appropriately evaluate the consequences of improved quality of life and minimize healthcare expenditures. More research examining the relationship between self-care of chronic disease and healthcare organizations' outcomes, is needed. Raising more awareness of this concept among professionals is therefore needed and can serve as a guide in conducting more research and the development of public health policies, self-care disease management programs, education sessions, practical interventions, or evaluation tools for people living with chronic diseases.

\section{Abbreviations}

CDC: Centers for Disease Control and Prevention.

WHO: World Health Organization. 


\section{Declarations}

\section{- Acknowledgements}

Not applicable.

\section{- Funding}

This research received no specific grant from any funding agency in the public, commercial, or not-forprofit sectors.

\section{- Availability of data and materials}

All data generated or analyzed during this study are included in this published article.

\section{- Ethics approval and consent to participate}

Not applicable.

\section{- Competing interests}

The authors declare that they have no competing interests.

\section{- Consent for publication}

Not applicable.

\section{- Authors' contributions}

JA and IA contributed in designing and completing the concept analysis, in the analytic process, and drafting the first version of the manuscript. All authors read, reviewed, and approved the final manuscript.

\section{- Authors' details}

1 Medical-Surgical Nursing Department, King Saud University-College of Nursing, Badran Al Omar Street, Riyadh 11451, Saudi Arabia.

2 Community and Mental Health Nursing Department, King Saud University-College of Nursing, Badran Al Omar Street, Riyadh 11451, Saudi Arabia.

\section{References}

1. Anderson, J. M. (1990). Home care management in chronic illness and the self-care movement: An analysis of ideologies and economic processes influencing policy decisions. ANS. Advances in Nursing Science, 12(2), 71-83. doi: 10.1097/00012272-199001000-00010 
2. Blankers, M., Koeter, M. W. J., \& Schippers, G. M. (2011). Internet therapy versus internet self- help versus no treatment for problematic alcohol use: A randomized controlled trial. Journal of Consulting and Clinical Psychology, 79(3), 330. doi: 10.1037/a0023498

3. Centers for Disease Control and Prevention. (2018). Health systems approaches to preventing chronic disease: New partners, new tools, and new strategies. Retrieved August 20, 2021, from https://www.cdc.gov/pcd/current_issue.htm

4. Clark, N. M. (2003). Management of chronic disease by patients. Annual Review of Public Health, 24(1), 289-313. doi: 10.1146/annurev.publhealth.24.100901.141021

5. Godfrey, C. M., Harrison M. B., Lysaght, R., Lamb, M., Graham, I. D., \& Oakley, P. (2011). Care of selfcare by other-care of other: The meaning of self-care from research, practice, policy and industry perspectives. International Journal of Evidence Based Healthcare, 9(1), 3-24. doi: 10.1111/j.17441609.2010.00196.x

6. Haug M. R., Wykle M. L., \& Namazi K. H. (1989). Self-care among older adults. Social Science \& Medicine, 29(1), 171 - 83. doi: 10.1016/0277-9536(89)90165-2

7. Høy, B., Wagner, L., \& Hall, E. O. (2007). Self-care as a health resource of elders: an integrative review of the concept. Scandinavian Journal of Caring Sciences, 21(4), 456-466. doi: 10.1111/j.14716712.2006.00491.x

8. LeBlanc, R. G., \& Jacelon, C. S. (2018). Self-care among older people living with chronic conditions. International Journal of Older People Nursing, 13(3), e12191. doi: 10.1111/opn.12191

9. Levin, L. S. (1979). Self-care: New challenge to individual health. Journal of American College Health Association, 28(2), 117-120. doi: 10.1080/01644300.1979.10392909

10. Lorig, K. R., \& Holman, H. R. (2003). Self-management education: history, definition, outcomes, and mechanisms. Annals of Behavioral Medicine, 26(1), 1-7. doi: 10.1207/S15324796ABM2601_01

11. McEwen, M., \& Wills, E. (2014). Theoretical Basis for Nursing (4th ed.). Philadelphia: Lippincott Williams \& Wilkins.

12. Moore, L., Frost, J., \& Britten, N. (2015). Context and complexity: the meaning of self-management for older adults with heart disease. Sociology of Health \& IIIness, 37(8), 1254-1269. doi: 10.1111/14679566.12316

13. Orem, D. (1959). Guides for developing curriculum for the education of practical nurses. Washington, DC: U.S. Dept. of Health, Education, and Welfare, Office of Education.

14. Peters-Klimm, F., Freund, T., Kunz, C. U., Laux, G., Frankenstein, L., Müller-Tasch, T., \& Szecsenyi, J. (2013). Determinants of heart failure self-care behaviour in community-based patients: a crosssectional study. European Journal of Cardiovascular Nursing, 12(2), 167-176. doi: $10.1177 / 1474515112439964$

15. Richard, A. A., \& Shea, K. (2011). Delineation of self-care and associated concepts. Journal of Nursing Scholarship, 43(3), 255-264. doi: 10.1111/j.1547-5069.2011.01404.x

16. Riegel, B., Dunbar, S. B., Fitzsimons, D., Freedland, K. E., Lee, C. S., Middleton, S., Stromberg A., Vellone E., Webber D. E., \& Jaarsma, T. (2019). Self-care research: Where are we now? Where are we going? 
International Journal of Nursing Studies, 103402. doi: 10.1016/j.jinurstu.2019.103402

17. Rodgers, B. L., \& Knafl, K. A. (2000). Concept analysis: An evolutionary view. In T. Eoyang (Ed.), Concept development in nursing: Foundations, techniques, and applications. Philadelphia: Saunders.

18. Schulman-Green, D., Jaser, S., Martin, F., Alonzo, A., Grey, M., McCorkle, R., Redeker, N. S., Reynolds, N., \& Whittemore, R. (2012). Processes of self-management in chronic illness. Journal of Nursing Scholarship, 44(2), 136-144. doi: 10.1111/j.1547-5069.2012.01444.x

19. Sundsli, K., Espnes, G. A., \& Söderhamn, O. (2013). Being old and living alone in urban areas: the meaning of self-care and health on the perception of life situation and identity. Psychology Research and Behavior Management, 6, 21. doi: 10.2147/PRBM.S46329

20. Thorne, S., Paterson, B., Russell, C., \& Schultz, A. (2002). Complementary and alternative medicine in chronic illness as informed self-care decision making. International Journal of Nursing Studies, 39(7), 671-683. doi: 10.1016/S0020-7489(02)00005-6

21. World Health Organization (WHO). (1984). Health education in self-care: Possibilities and limitations (Report No. HED/84.1). https://apps.who.int/iris/handle/10665/70092

22. World Health Organization (WHO). (2019) Self-care can be an effective part of national health systems. Retrieved November 20, 2019, from https://www.who.int/reproductivehealth/self-carenational-health-systems/en/

23. World Health Organization (WHO). (2013). Q+A about Self-Care. Retrieved August 19, 2021, from https://www.who.int/reproductivehealth/self-care-interventions/questions-answers/en/

24. Wilkinson, A., \& Whitehead, L. (2009). Evolution of the concept of self-care and implications for nurses: A literature review. International Journal of Nursing Studies, 46(8), 1143-1147.

doi: 10.1016/j.jpurstu.2008.12.011 